\title{
Cultura, Símbolos y Significados en la Etnicidad Otomí
}

\author{
Juan Luis Ramírez Torres \\ CESAP, Facultad de Medicina-UAEM
}

\begin{abstract}
Resumen: Las innovaciones culturales en los grupos indígenas, en más de una ocasión, son interpretadas como factores que propician la pérdida de la etnicidad, ante ello, el presente trabajo ofrece una perspectiva que subraya el papel actuante de las sociedades indias, y en donde las innovaciones culturales no son exclusivamente sinónimas de aculturación y abandono de la identidad, sino que también implican un proceso de resignificación de los símbolos culturales heredadados con el objeto de adecuarse, en tanto que unidad social específica, a las nuevas condiciones que la historia les presenta. Para ilustrar esto se recurre a la descripción etnográfica del caso otomí en el Estado de México, analizando la permanencia de símbolos específicos y su relación con la reproducción étnica a nivel local.

Abstract: The cultural innovations of indigenous groups are understood as factor that causes the lost of ethnicity. In relation to this, this paper is focused on a perspective that remarks the active role of Indians societies, however they also imply a process of new meaning of cultural symbols inside the new conditions its represents.
\end{abstract}

\section{Introducción}

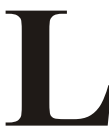

as innovaciones culturales en las sociedades indígenas, en más de una ocasión, son interpretadas como factores que propician la pérdida de la etnicidad, tal visión implica una postura que deja a estos pueblos en la condición de meros receptores, lo que equivale a una forma más de discriminación, tan sutil como el paternalismo, pero que a fin de cuentas parte de una postura de poder sobre las minorías étnicas, reproduciendo así el dominio que éstas han padecido durante centurias.

Ante ello, el presente trabajo ofrece una perspectiva que subraya el papel actuante de las sociedades indias, y en donde las innovaciones culturales no son exclusivamente sinónimas de aculturación y pérdida de la identidad étnica original, sino que también implican un proceso de resignificación de los símbolos culturales heredadados, con el objeto de adecuarse, en tanto que unidad social específica, a las nuevas 
condiciones que la historia les presenta. Sobre ello cabe la observación de Maurice Godelier quien señala:

....adaptación y desadaptación existen puesto que las sociedades nunca son totalidades completamente "integradas", como pretenden los funcionalistas, sino totalidades en las que la unidad es el efecto "provisionalmente estable" de una compatibilidad estructural que permite a las diferentes estructuras reproducirse y a su articulación mantenerse hasta que la dinámica interna y externa de estos sistemas impide a estas totalidades seguir existiendo como tales. La noción de equilibrio, lejos de significar ausencia de contradicciones, significa de hecho una cierta regulación de las contradicciones internas y externas del sistema; regulación que mantiene su unidad (Godelier, 1976: 43).

De esta manera es que los sistemas sociales y culturales, en tanto que totalidades, se mantienen en una dinámica nutrida de contradicciones constantes, las cuales no significan su aniquilamiento sino, por el contrario, dichas contradicciones ocurren en tanto que éstas conforman una unidad existente, es decir, en este caso, una cultura concreta, un sistema simbólico, no libre de contradicciones, sino dialéctico, gracias a lo cual un determinado sistema cultural, correspondiente a una sociedad específica, ofrece un marco cognoscitivo-práctico por cuya intermediación ese grupo humano logra adecuarse a su hábitat y entorno social, y a las modificaciones futuras que en ambos acontezcan.

Una manera de abordar esa dinámica contradictoria que da forma al grupo social, es por medio de sus representaciones simbólico-culturales, y de las que el mismo Godelier indica que es "a partir de estas representaciones (que) los individuos o los grupos actúan sobre el medio" (Godelier, 1976: 43) en que habitan, es decir, en que son sociedad humana. Si el sistema se encuentra en continua adaptación-desadaptación, entonces sus componentes simbólicos se ven modificados a lo largo de este proceso, deshechando elementos viejos y adoptando otros nuevos, a la manera del caleidoscopio, ese "instrumento que contiene también sobras y trozos, por medio de los cuales se realizan ordenamientos culturales" (Levi-Strauss, 1992: 61). Tales ordenamientos culturales, que parten de una estructura, interactúan con la historia, esto es, con las condiciones sociales y materiales en que se ubican los eventos humanos. Al respecto Marshall Sahlins considera:

La historia es ordenada por la cultura, de diferentes maneras en diferentes sociedades, de acuerdo con esquemas significativos de las cosas. Lo contrario también es cierto: los esquemas culturales son ordenados por la historia, puesto 
que en mayor o menor grado los significados se revalorizan a medida que van realizándose en la práctica (Sahlins, 1988: 9).

De esta manera, la cultura en su dinámica modifica los significados de sus componentes, conforme lo exija la práctica, las experiencias que dicten sus procesos de adecuación en el devenir histórico, para que esto ocurra se requiere un espacio donde se concrete tal dinámica, dicho espacio es el grupo social que construye cotidianamente una cultura y una historia permanentemente cambiantes.

Lo considerado hasta aquí es observado a continuación en el caso de la población otomí del Estado de México (entidad federativa de la república mexicana colindante con la capital del país), particularmente la asentada en el valle de Toluca. Este grupo étnico forma parte de la familia lingüística otomí-pame, junto con las lenguas mazahua, ocuilteca, matlazinca, pame y chichimeca-jonaz (Soustelle, 1993), ubicadas las cuatro primeras en Mesoamérica y las dos últimos en el norte de México. Las comunidades que la componen están inmersas en una región de importantes corrientes migratorias e influencias culturales externas, pese a lo cual mantiene su sentido indígena. Los poblados otomíes -y vecinos de los mazahuas- que existente actualmente en el Estado de México se encuentran en los municipios de Acambay, Aculco, Chapa de Mota, Ixtlahuaca, Jilotepec, Lerma, Morelos, Otzolotepec, Temascalcingo, Temoaya, Timilpan, Villa del Carbón y Xonacatlán, a una distancia de entre 50 y 150 kilómetros de la ciudad de México. Estos lugares se ubican principalmente en la parte serrana que delimita al valle de Toluca, en su parte oriental, por lo que la mayoría de poblados se encuentran asentados sobre suelos de nivel irregular, en paisajes boscosos de clima frío e irrigados por algunos arroyos que atraviesan sus extensiones.

Cultivan maíz, trigo, cebada, haba; cuentan con árboles frutales como capulín, tejocote, manzano y peral; crían borregos, pollos y guajolotes; poseen ocasionalmente animales de tiro y carga como mulas, burros, caballos y bueyes. La producción de maíz y haba se destina principalmente al autoconsumo y para el mercado cuando hay excedentes, a los que se suman las cosechas de trigo y cebada.

Los otomíes campesinos de la presente centuria, son producto inmediato de la historia reciente que arranca del reparto agrario ocurrido durante los gobiernos posrevolucionarios en la primera mitad del presente siglo. Sin embargo, la generación compuesta por los hijos 
de aquellos primeros campesinos que recibieron dotación de tierras, accedieron a una parcela heredada -frecuentemente por vía paterna, aunque también se tiene noticia de herencia matrilateral en comunidades de los municipios de Acambay y Otzolotepec-, por lo que el paso de una a otra generación de las mismas extensiones de cultivo, dio inicio a la sobrecarga demográfica que rebasó la capacidad de sustentación, es decir, el límite que permite mantener a una población humana (Hardesty, 1979: 197-212), en este caso, la de las comunidades otomíes. Surge en consecuencia el mini-fundismo, hacia las décadas de los sesenta y setenta se agudiza el proceso de atomización de las tierras agrícolas entre los campesinos del valle de Toluca, propiciando un importante flujo migratorio hacia la ciudad de México, destacando el caso mazahua en los municipios de Ixtlahuaca y San Felipe del Progreso (Arizpe, 1978), entre otros, a los que se suman por supuesto, los otomíes y cuyas dinámicas migratorias, en lo general, son semejantes: unos lo efectúan en periodos cortos -regresando a su localidad cada ocho o quince días-, mientras otros lo hacen en tiempos más prolongados -durante meses-; a diferencia del tercer grupo compuesto por los migrantes permanentes, quienes ya no regresan a su comunidad de origen. Aquellos colaboran aun en la economía del grupo doméstico, con dinero, trabajo y especie; mientras que éstos quiebran con todo vínculo de reciprocidad.

Bajo tales condiciones, las nuevas generaciones han optado por migrar hacia centros urbanos como estrategia económica de doble efecto: uno, disminuir la presión demográfica sobre la capacidad de sustentación; dos, obtener ingresos monetarios para inyectarlos en la economía familiar y comunitaria de origen, complementando así los recursos que la pura producción agropecuaria no provee. De esta forma, el éxodo evita un colapso ecológico y preserva la existencia de la comunidad indígena; la emigración, por lo tanto, no significa la desaparición de la población indígena, como ciertas lecturas superficiales podrían llegar a suponerlo, ya que el hecho de que una parte de los migrantes adopten nueva residencia ajena, espacial y culturalmente de su localidad nativa, no implica que el total de quienes salen por motivos de trabajo rompan con su lealtad étnica y la reciprocidad económica para con su pueblo; muy por el contrario, esa porción desplazada a las urbes que sigue vinculada con el grupo de origen, es fuente de bienes que son llevados por ellos mismos a su comunidad para complementar el consumido de aquellos otros que 
radican en el poblado indígena. Este mecanismo ha posibilitado la reproducción de las comunidades otomíes de origen, en tanto que espacio físico y social, de donde resulta una reproducción también étnica.

Sin embargo, dicha reproducción no es copia fiel de una supuesta condición étnica original y auténtica, tradicional a ultranza, ni estática, ya que los poblados otomíes experimentan modificaciones en la organización familiar, comunitaria y en las pautas culturales, como producto de las presiones económicas que el minifundismo y la emigración les imponen. Pero al mismo tiempo estos cambios cumplen la función de estrategias de readecuación frente a las nuevas condiciones locales, regionales y nacionales que se viven, cambios que son realizados sin destruir las redes de reproducción étnica que se recrean al interior de los límites locales. De tal manera que el cambio cultural es ambivalente: por un lado, modifica las formas culturales y, por el otro, reitera la permanencia de la comunidad en su peculiaridad étnica.

\section{Símbolos antiguos y recientes para la identidad otomí}

Para ilustrar este proceso veamos ahora algunos ejemplos del cambio cultural indígena a lo largo de su historia; con dicho material es posible registrar las modificaciones culturales ocurridas, lo que, con todo, no ha sido motivo para que las comunidades otomíes hayan abandonado su cohesión étnico-comunitaria.

En el pasado prehispánico, los otomíes eran tributarios de Tenochtitlan, centro dominante al momento de la Conquista; se dedicaban a la agricultura, teniendo sementeras y graneros; cultivaban maíz, frijol y calabaza. Por igual practicaban la cacería de conejos, liebres, codornices y venados (Sahagún, 1979: 602-3); además del ejercicio de la pesca, debido a que en el valle de Toluca se albergaba un sistema lacustre (Carrasco, 1979: 67). Ejemplo de ello es la laguna de Santa Cruz Atizapán -en el municipio del mismo nombre ubicado en la región que nos ocupa-, donde existen vestigios arqueológicos de un asentamiento que ofrece evidencias de que ahí se poseían abundantes recursos propios del medio lacustre, lo que se asociaba, a su vez, con actividades relativas a la caza, pesca y recolección de la fauna y flora acuática (Sugiura y Serra, 1983: 14). Con todo, para el siglo XVI todavía el cultivo de maíz posibilitaba un consumo por demás variado: en grano tierno (jilotes), maduro, en tamales, atoles, asado, en forma 
cruda o cocida, incluso agrio. A éste se agregaba el cultivo de frijol y calabaza, el consumo de chile, huauhtli, chía, tomate, maguey, chayote, camotes, además del capulín, tejocote, aguacate, zapote, guayaba, ciruela, anona, papaya y piña (Carrasco, 1979: 53-58).

Con el posterior dominio español los ecosistemas del valle de Toluca, el vecino valle de Ixtlahuaca, y el norte y sur de lo que hoy es el Estado de México fueron alterados; las amplias extensiones ocupadas por ciénagas, particularmente en el valle de Toluca, sustituyeron en parte los usos agrícolas y lacustres por los de pastizales. Este cambio de las actividades económicas indígenas a las impuestas por los ibéricos, obedeció a los intereses de estos últimos por desarrollar una producción ganadera que se implantó sobre suelos antes agrícolas, alterando la compaginación de extensiones de cultivo junto con las superficies boscosas y las lagunas que explotaba anteriormente la población nativa. Se importan nuevas especies vegetales y animales, en el entorno aparecen el trigo en Ixtlahuaca, Ocuilan, Malinalco, Tenancingo, Sultepec y Temascaltepec; la cebada, en Sultepec y Tenango; y la caña de azúcar en Texcaltitlán; por igual se encuentra el plátano, durazno, pera, prisco, membrillo, granado, higuera, manzana, naranja y limones; lechuga, rábano, col, coliflor y betabel (Quezada, 1972: 103-104). La ocupación de extensiones de tierra para la cría de ganado mayor y menor -vacuno, lanar y porcino-, también alteró el paisaje en donde los animales domesticados en la época precolombina contaban a especies como el guajolote y el tepescuintle, por ejemplo. Por lo tanto, el dominio hispano afectó y alteró aspectos de orden social, político, económico e ideológico, al mismo tiempo que modificó el sistema natural y la relación hombre-naturaleza, como ha sido señalado para la Nueva España (Mc Clung de Tapia, 1990). El factor ecológico, en consecuencia, estuvo asociado con lo económico, político y cultural, por lo que el dominio hispano implicó modificaciones tanto en las relaciones sociales y sus configuraciones culturales, como en las relaciones hombre-naturaleza y en la recomposición de los ecosis-temas naturales. Al respecto cabe tener presente lo considerado por Marshall D. Sahlins, quien apunta a propósito de la cultura y la ecología: "Existe un intercambio entre la cultura y el medio ambiente, tal vez un intercambio dialéctico continuo, cuando las culturas, deseosas de adaptación, transforman su medio geográfico y deben responder al reto de las nuevas condiciones físicas que provocaron" (Salhins, 1964: 159). En este proceso 
dialéctico naturaleza-sociedad, el sistema mágico-religioso se ofrece como un interesante campo de observación del cambio cultural otomí, al mismo tiempo que constituye un fundamental venero de símbolos y referentes étnicos, por lo que nos detendremos en ello.

A lo largo de los registros etnográficos, desde los correspondientes al siglo XVI hasta los actuales, muestran en forma constante la presencia de los componentes simbólicos: agua, árbol, cerro, cueva y fuego; si bien éstos son universales (Chevalier y Gheerbrant, 1986), cada sociedad se los ha apropiado al grado de convertirlos en signos de su etnicidad. Toda región habitada, en tanto que microcosmos perteneciente a cada comunidad cultural determinada, posee un centro, símbolo de su origen mitificado y por ende, lugar sagrado por excelencia (Eliade, 1979: 42), el cual puede estar marcado por un lago, un árbol, una montaña, una cueva o una hoguera.

De esta forma es que en el pasado prehispánico otomí, el culto a los dioses del agua se celebra principalmente en las cimas de los cerros (Carrasco, 1979: 217), lo que nos hace ver en estos sitios un espacio propicio para las hierofanías, es decir, para las manifestaciones de lo sagrado (Eliade, 1985: 19). Otro lugar propio de la geografía de la región es la cueva, al respecto en la Relación de Querétaro se menciona al Padre Viejo y a la Madre Vieja como la pareja original en la cultura otomiana, de ella procedían todos los nacidos, éstos habían salido de unas cuevas que están en un pueblo de nombre Chiapan. A su vez, Padre Viejo, junto con otra divinidad, Otonteuctli, son dioses del fuego; siendo el culto a éste tal vez el más importante entre los otomíes, por ejemplo, presidía numerosas ceremonias caseras bajo la forma de fuego del hogar (Carrasco, 1979: 135 y 161). Es precisamente en una cueva donde se gesta el sincrético culto al actual Señor de Chalma, anterior a la cristianización española, se veneraba al dios llamado Oztoteotl y a quien se le ofrecía el sacrificio de niños, lo que sugiere que este ídolo era una forma de Tláloc, divinidad del agua (Carrasco, 1979: 150); este santuario ha sido lugar de culto para los pueblos del valle de Toluca (Mendizábal, 1946: 519), entre los que se cuenta a los otomíes.

Otonteuctli poseía otros nombres: Xocotl, Cuecuex u Ocoteuctli, este último muestra el carácter sagrado del árbol, ya que ocote es el nombre genérico de diversas especies de pinos que producen resina (Martínez, 1987: 645) -en la región de estudio se hallan el Pinus 
teocote y el Pinus patula entre otras especies (IIIGEC, 1993: 43)- y dadas sus cualidades combustibles se entiende la asociación simbólica entre fuego y árbol, ambas entidades hierofánicas, por lo que no resulta extraño que fuesen adoradas en el espacio ritual de los cerros, como lo indica información de fuentes históricas al relatar el caso de la adoración a un árbol que crecía en la cima de un cerro (Carrasco, 1979: 160).

Este conjunto simbólico se mantiene presente para el siglo actual, tanto en la esfera comunitaria como en la doméstica. Así al ya citado Santuario del Señor de Chalma, debe agregarse uno más, el del Señor del Cerrito, en Santa Cruz Tepexpan, municipio de Ixtlahuaca, que al igual que en el primero, es sitio de arribo de peregrinaciones y cuya llegada al templo es precedida por el culto al árbol: un ahuehuete en Chalma (Giménez, 1978), y el de varios árboles durante el ascenso a la cumbre, en Tepexpan, en los cuales son colgados objetos (fotos, cabellos, ropas) que piden un favor (de salud, económico o legal, entre otros) o agradecen el milagro recibido.

Relativo al ámbito doméstico, hacia la tercera década del presente siglo, Jacques Soustelle encuentra en El Sitio, municipio de Ixtlahuaca, una "aldea otomí absolutamente indígena, típica, en la que la raza es pura y la lengua tradicional la única que se emplea" (Soustelle, 1980: 42). Esa localidad constituida de chozas dispersas, cada una de ellas acompañada de un pozo, un granero y un oratorio, y a pesar de calificarlas este autor de "típico", observa que en el pasado las casas estaban cubiertas de tejamanil, pero en ese momento los indígenas ya cocían sus tejas en horno de adobes (Soustelle, 1980: 42-43). La vida religiosa doméstica poseía su espacio sagrado en el oratorio: pequeño edificio cuadrado blanqueado con cal, en cuyo interior había imágenes de santos, flores, a veces una botella vieja o un foco eléctrico a manera de ofrenda (Soustelle, 1980: 43); el oratorio en tiempos anteriores, era el espacio donde los viejos adoraban ídolos de barro cocido a los que ofrendaban maíz y hasta carne (Soustelle, 1980: 54); cabe señalar que este rasgo cultural no les había sido exclusivo a los otomíes, ya que este etnólogo, en otro momento, menciona la existencia de oratorios también en la región de Ixtlahuaca entre comunidades mazahuas, vecinas a las otomíes (Soustelle, 1935). Pero, si bien no hay noticias de un oratorio doméstico prehispánico como el visto por este autor, sí por el contrario, en ese mismo ámbito familiar de la casa otomí, el fogón es el símbolo ritual más prominente, constituyéndose en centro que reúne 
la animación de la vida, a través de las llamas y del aniquilamiento, por medio de la simbolización de las cenizas, marca de la ancestralidad (Galinier, 1990: 145).

En consecuencia, el tránsito de la sociedad mesoamericana prehispánica a la Colonia, implicó modificaciones que impactaron las esferas ecológicas, económicas, políticas y religiosas. Posteriormente, con la independencia de México y su ulterior evolución durante el siglo $\mathrm{XX}$, los cambios continuaron, de esto hay que resaltar dos hechos que se constituyen en paradoja: el cambio cultural ha modificado la imagen etnográfica otomí y la existencia otomí continua, es decir, los cambios de forma no han alterado la permanencia del contenido, esto es, la del Ser otomí.

De esta manera, el culto a Otonteuctli ha desaparecido; la dieta se ha modificado junto con las alteraciones del hábitat y su consecuente desaparición de especies de flora y fauna nativas; las casas modificaron la pauta del techo de tejamanil al de teja de barro; mientras que los oratorios, por su parte, transitaron del culto a ídolos de barro cocido a imágenes católicas; más aún, los oratorios, como forma cultural, son compartidos con un grupo diferenciado étnicamente de los otomíes. Todo esto lleva a la pregunta sobre ¿cómo son entonces los otomíes típicos y puros?, ¿los que conoció Soustelle durante la tercera década del siglo XX?, ¿ ¿los que adoraban ídolos de barro y vivían bajo techos de tejamanil?, ¿los otomíes poseen símbolos culturales peculiares de su etnicidad?, luego entonces, ¿los oratorios son una expresión cultural típicamente otomí o mazahua? Para avanzar en la respuesta a tales interrogantes observamos la dinámica cultural indígena en los albores del año 2000.

\section{El caso de una comunidad otomí}

Los actuales otomíes desarrollan actividades tanto campesinas como de otros tipos que los economistas ubicarían dentro del rubro actividades secundarias y terciarias, ocupaciones cuya remuneración se expresa bajo la forma de salario, lo que a su vez dio pie a pronosticar procesos de proletarización en la dinámica campesina (R. Bartra, 1980: 16). Sin embargo, a más de tres décadas de iniciado el proceso migratorio -hacia finales de los sesenta-, las comunidades subsisten a pesar de la penetración de entidades ajenas a su cultura inmediata anterior, como numerosas escuelas, las menos abundantes unidades de salud institucionales, los programas de desarrollo agropecuario y la 
presencia de diversos organismos oficiales y privados, pese a lo cual la conservación del sentimiento de pertenencia a su pueblo, la perseverancia en las fiestas comunitarias y familiares, amén de la reproducción biológica de los nuevos miembros a partir de parejas oriundas del lugar o de localidades vecinas, permite sugerir que las comunidades otomíes actuales se reproducen étnicamente, manteniendo rasgos antiguos de su economía agrícola y agregando otros canales de ingresos como el trabajo asalariado y el comercio, los cuales, antes que romper con sus instituciones comunitarias, permiten contar con recursos para reproducirlas como tales.

En tal dinámica se encuentra San Mateo Capulhuac -perteneciente al municipio de Otzolotepec, con cabecera en el poblado mestizo de Villa Cuauhtémoc-; tiene una superficie de 1760 hectáreas, compuesta de lomas. La población ascendía en 1990 a 5129 habitantes, de los cuales 2640 eran hombres y 2489 mujeres. A excepción del conjunto del centro del pueblo, el resto del lugar se compone de casas dispersas junto a su tierra de cultivo. El poblado está rodeado por cerros, la inclinación del terreno mira hacia el Xinántecatl y Toluca. Hacia el norte, se encuentra el cerro La Columna, en otomí tziteje (del que no se tiene traducción precisa); hacia el este, e irguiéndose sobre el pueblo, se ubica el cerro de La Corona, tzimaye, en otomí; mientras que del lado sureste se halla el cerro, Ojo de Agua, lampuete en la lengua indígena. Los nombres nativos no fueron identificados con exactitud, pareciera ser que el registro de topónimos en otomí, en este caso particular, sobre los cerros, está perdiéndose. Existe una zona boscosa, de entre sus usos destaca el del cedro para carbón; el oyamel es utilizado como madera para la construcción de graneros. Por su territorio atraviesa el río Ajolotes, además cuenta con la presa Ocotitos.

Las actividades agrícolas y de explotación del bosque (tala de especies para carbón y madera) ocupan las mayores superficies del lugar: 46 y 44\% respectivamente; en tanto que los usos del suelo para habitación (3\%), praderas y pastos para la cría de borregos muestran pequeña porciones: 7\% (Álvarez Lobato, 1991). Junto a esto la emigración es marcada, principalmente entre la población juvenil, aunque los adultos, hombres y mujeres, también salen de la localidad; los motivos son económicos -minifundismo, escasos ingresos monetarios, falta de fuentes alternativas de empleo-. De la población económicamente activa se ocupan en el sector secundario $12.9 \%$, y en 
el terciario $30.6 \%$, lo que significa que $43.5 \%$ de este conjunto desempeñe actividades distintas a las labores del campo, mientras que $56.5 \%$ se sostiene dentro del sector primario (INEGI, 1991) asociadas a la economía campesina, caracterizada ésta por articularse a la organización familiar -como lo reconocen Eric Wolf (1978) y Armando Bartra (1982) para las sociedades campesinas contemporáneas en lo general-y dentro de la cual se producen y consumen los bienes obtenidos tanto de la labranza como de la cría de animales, y en menor proporción de la caza esporádica y la recolección. Esto repercute en la reorganización de la unidad doméstica campesina, en cuyo interior se modifican las pautas en la división del trabajo, los pesos dados a los ingresos en especie y el trabajo y la función atribuida a los ingresos en dinero.

Las anteriores cifras permiten una aproximación a la reorganización que en las recientes décadas ha experimentado la unidad doméstica campesina, célula básica de organización social y económica de la localidad. Es así que ante el proceso minifundista -a partir de la degradación ecológica de ecosistemas naturales y agroecosistemas-, y su resultante flujo emigratorio, las unidades familiares ahora articulan la producción y el consumo de productos cultivados, criados, cazados o recolectados -ingresos en especie-con otros adquiridos por compra, lo que les lleva a la necesidad de obtener dinero. Gracias a la coparticipación de ambos espacios se reproduce económicamente un conjunto de individuos que forman una familia, instalada en una localidad rural y de la cual una porción migra periódicamente, regresando en lapsos más o menos cortos a comunidades como la de San Mateo Capulhuac.

Pasando del plano socioeconómico al simbólico, encontramos que en esta comunidad, los cerros son espacios sacralizados en la medida en que se erigen en escalas que metafóricamente les permite comunicarse con entidades sagradas; así es que se puede entender la presencia de cruces en lo alto de ellos, punto de contacto con lo divino. Al respecto Mircea Eliade (1979:45-46), señala que las montañas son frecuentemente considerados centro del mundo reafirmando el etnocentrismo inherente a todo pueblo. De entre los cerros que rodean a San Mateo, sobresale el del Ojo de Agua, lampuete, nombre que recibe dado que al pie del mismo emana agua, también éste, símbolo fundamental de origen, fecundación, purificación y regeneración (Eliade, 1979: 165-174), ambas características: cerro-escala y 
agua-vida, lo convierten en sitio propicio para la elaboración de construcciones simbólicas de lo sagrado. Este cerro está ubicado precisamente a espaldas de la iglesia, la que también se encuentra en una parte alta del quebrado paisaje, pudiéndose mirar desde el campanario del templo el cerro Ojo de Agua, de aquí que resultan asociados los componentes agua y cerro, es decir, origen-revitalización y centro del universo. La existencia de dos cumbres sacralizadas en Capulhuac, una donde se levanta la iglesia y otra la del Ojo de Agua, tiene explicación con lo considerado por Eliade al indicar que la existencia del centro no significa que sea exclusiva de un lugar, sino que puede darse la presencia de varios centros (Eliade, 1979: 42-43). En este caso, considero que el cerro es marca del culto al agua, de antecedentes precolombinos; mientras que en el templo católico se rinde culto al santo patrón, herencia ésta de resignificaciones gestadas durante la Colonia. Hoy en día, producto de un proceso de resignificación, el primero resulta, en tanto que símbolo acuático, indicativo de su origen primigenio, mientras que el segundo, se erige como protector de la comunidad.

Otro ejemplo más de permanencias culturales, se encuentra en el relato contado por una terapeuta tradicional de Capulhuac, a propósito de las cuevas, en un sitio así

... había unos muñecos de barro, y adentro estaban unas personas con mucha comida, piernas de pollo, tortillas. (En un momento dado) esas gentes se salieron, y entonces mi hermano echó una miada a los muñecos y entonces (nos llevamos) hartas piernas de pollo que había y muchas tortillas, no todas porque eran muchas. Cuando se encuentran lugares así, debe orinarse sobre las figuras, porque sino los que toman la comida quedan ciegos.

Este relato nos muestra a la cueva como fuente de abundancia, cuyo origen sagrado conlleva el inherente peligro de contaminación (Douglas, 1973), por lo que debe purificarse la comida a través del símbolo acuático patentizado en el acto de orinar. Esto es evidencia del carácter hierofánico que la cueva sigue conservando hasta nuestros días.

Durante las celebraciones en honor a san Mateo en Capulhuac, en el interior de la iglesia y al pie del altar, se colocan gran cantidad de cirios (se ha llegado a contar cerca de un centenar), que a la media luz del lugar hace resaltar sus llamas en un solo cuerpo luminoso, lo que contrasta con la semipenumbra del templo; esta escena vista desde el exterior, rememora una cavidad - la cueva- donde reposa el santo 
patrón animado por el calor del fuego. En el atrio se encuentra un pequeño cubo, de $1.30 \mathrm{~m}$ aproximadamente por lado, sobre el cual se levanta una cruz de piedra, en su parte frontal, que mira a la entrada de la iglesia, en el centro y ligeramente hacia arriba, tiene un orificio en el que se colocan veladoras, el fuego se presenta nuevamente. Esta característica común que evoca a la ancestral cueva es fundamentalmente símbolo arquetípico de la matriz materna, por lo que sus significados remiten al origen y al renacimiento (Chevalier y Gheerbrant, 1986: 263). En consecuencia, la ritualidad de la fiesta patronal, que reúne símbolos permanentes en la estructura cultural otomí -agua, fuego y cueva-, reitera el origen primigenio de esta localidad indígena al regresar metafóricamente a la matriz representada por el interior de la iglesia.

Terminada la misa, punto culminante de la fiesta, los habitantes de la comunidad salen del templo renovados, y entonces el símbolo ígneo de los cohetes y fuegos artificiales celebra el renacimiento de los hombres y mujeres de San Mateo Capulhuac. Estos mismos hombres y mujeres son los que labran la tierra, cosechan maíz, viajan a ciudades distantes para ganar dinero que destinan a la economía doméstica y comunitaria, y que permite pagar el refresco traído de la industria urbana, comprar el cuaderno del niño para la escuela, costear las ceras al santo, todo esto para seguir siendo el pueblo de San Mateo Capulhuac. Así, se articulan en un mismo corpus social las opciones de subsistencia que oscilan entre la producción agrícola y los ingresos monetarios; economía campesina que ocurre en el escenario religioso compuesto de símbolos que reiteran su ancestralidad y pertenencia comunitaria hoy vigente y viva.

\section{Dinámica y etnicidad}

Esta comunidad se presenta como una población otomí, así lo entienden sus habitantes y los vecinos de éstos, lo que responde a la definición de Fredrik Barth, quien considera los aspectos de autoperpetuación biológica, valores culturales comunes, integrada por un campo de comunicación e interacción, y por autoidentificarse y ser identificados por otros como entidad de peculiaridades étnicas (Barth, 1976: 11).

La lengua materna ha sido un indicativo importante en la identificación de los grupos indígenas en México, sin embargo, los procesos de cambio cultural, inherentes a toda sociedad, aunado al 
rápido proceso de transformación social ocurrido paralelamente al proceso migratorio derivado del minifundismo en las décadas recientes, invita a replantear dicha visión. Las comunidades otomíes -como otras indígenas del país- abandonan paulatinamente el uso de la lengua original, el vestido y otros aspectos de una supuesta cultura propia. Con frecuencia se olvida que las formas asociadas con etnias específicas son producto de la Colonia, periodo durante el cual, al igual que ahora, las comunidades nativas dejaron las maneras culturales precolombinas y adoptaron, por la fuerza o de conformidad, innovaciones que hoy se han convertido en costumbres, en un proceso de apropiación y resignificación. Con todo, el número de hablantes indígenas sigue siendo, a falta de algo más palpable, el indicativo por excelencia para aproximarse al dato cuantitativo étnico y que coincide como un factor de autoidentificación adoptado como tal entre la misma población otomí del Estado de México, y a la que se suman otros factores como la pobreza y el sometimiento que han sufrido de antiguo (Lagarriga, 1974: 68).

La lengua otomí es ejercida en San Mateo Capulhuac, conforme las cifras del XI censo de 1990, en las siguientes proporciones. Los mayores a 5 años de edad y más, que hablan lengua indígena y no hablan español fue de 26 individuos, en tanto que aquellos que hablaban ambas lenguas sumaron la cantidad de 2199 personas, es decir 1.2 y $98.8 \%$ respectivamente. Quienes usan el otomí con mayor frecuencia -de acuerdo con lo observado en la localidad-son los ancianos y adultos, seguidos de los niños; los jóvenes evitan hablarlo, a pesar de que lleguen a dominarlo, o al menos, entenderlo; visto por sexos el asunto es entre las mujeres donde la lengua se reproduce con mayor perseverancia; de esta forma los niños aprenden la lengua otomí, ya sea por escucharlo o por que las mujeres les hablan de esa forma. Pero como -así lo considero- el idioma no es el único indicativo de lo étnico, ni el más importante, ni el último residuo de ello, pasemos a observar otros factores pertinentes.

Siguiendo la definición de Barth, otros componentes de lo étnico son la autoperpetuación biológica, los valores culturales comunes, la integrada por un campo de comunicación e interacción, y el autoidentificarse y ser identificados por otros como miembros de un grupo étnico. Sobre éstos se han observado, a través del registro etnográfico, los siguientes casos. 
Autoperpetuación biológica. Existe en la localidad, como en otros poblados de la región, la pauta, ciertamente no absoluta, de endogamia. Regularmente las parejas se forman entre jóvenes, hombres y mujeres de las misma comunidad de San Mateo, ya sea previa petición de la joven pretendida para esposa, por parte de una persona considerada importante y de respeto en la comunidad; o bien, recurriendo al robo de la novia, lo que implica la conformidad de ésta en irse con su novio; cuando ocurre lo primero se efectúa la ceremonia religiosa, católica, y posteriormente la fiesta que reúne a las familias de los nuevos esposos; en el segundo caso es común que después del robo, la pareja regrese ante los padres de la mujer para pedirles disculpas y realizar el contento: fiesta que patentiza el perdón otorgado y que marca la aceptación social para la nueva pareja; este regreso suele acompañarse con la presentación del producto de esa unión, es decir, el primer hijo, con lo cual se entabla una relación afectiva entre los ahora abuelos y el nieto.

Aunado a lo anterior, existe un mecanismo, relativamente reciente, que permite salvar el obstáculo de la permanencia de las nuevas generaciones fuera de la comunidad, este consiste en promover bailes públicos durante celebraciones del pueblo, principalmente en la fiesta patronal. En ellos se dan cita muchachas y muchachos solteros, principalmente de Capulhuac, momento durante el cual se permite el cortejo, por lo que el baile se constituye en espacio de nupcialidad y por lo tanto, de autorreproducción de la pauta endógama, lo que resulta en la creación de nuevos matrimonios, es decir, de nuevas unidades domésticas de producción campesina, que constituyen a su vez a la comunidad de San Mateo. Cabe señalar que ocurren también matrimonios efectuados con miembros de otras comunidades, sabiéndose de casos concretos realizados con personas de Jilotzingo o La Concepción, poblados vecinos, el primero otomí, el segundo mestizo, lo que indica que no existen impedimentos tajantes en términos étnicos. Con todo, la tendencia dominante es la endogamia, hecho que garantiza la reproducción biológica de la comunidad.

Valores comunes. Los valores comunes han quedado referidos en las descripciones anteriores relativas a los otomíes prehispánicos, de la Colonia, y de las actuales comunidades. Dicha comunión de valores permanece incluso por encima de los efectos aculturantes de la migración, particularmente entre los migrantes temporales, quienes son un sector conformado por hombres y mujeres, jóvenes y maduros 
solteros y casados, que se caracterizan por regresar los fines de semana, en las fechas religiosas, a los eventos del ciclo ritual de vida como bautizos, bodas y funerales; o que por igual asisten a las reuniones comunitarias para el cambio de mayordomos. Estos reencuentros con su parentela y localidad mantienen en vigor las relaciones entre los que se van y los que se quedan, de tal forma que el migrante temporal -a diferencia de los migrantes permanentes que ya no regresan y rompen con los lazos familiares y comunitarios- continúa con relaciones de reciprocidad: él aporta dinero, y su grupo doméstico, por ejemplo, puede cuidar de sus hijos; además, en las actividades religiosas suele entrar en relaciones de compadrazgo a propósito de un bautizo o de una mayordomía, por citar sólo dos posibilidades entre muchas otras. De tal forma que la lealtad y reciprocidad étnicas se sostienen más allá de las fronteras territoriales de la localidad y confirman su existencia y renovación en cada oportunidad ritual que se les presenta, por lo que el marco cultural otomí permanece y sus valores son compartidos tanto por los que se quedan como por lo que se van y regresan.

Campo de comunicación e interacción. Un punto sumamente importante, es que a pesar de que la comunicación no se realice siempre por medio de la lengua otomí, aquí se explica cómo el español se refunsionaliza al interior de la estructura cultural indígena, ya que vehiculiza, por medio de vocablos en castellano, una simbólica asumida como propiamente otomí: continúan, como antes se ha visto, en uso los símbolos del agua, del árbol, del fuego y de la cueva, sin que el medio verbal altere su carácter significativo para con la comunidad otomí; de esta suerte, el castellano se integra a la cosmovisión indígena. Paralelamente, y por medio de estos canales de comunicación que concretan el campo de comunicación (símbolos y lenguas otomí y español), los miembros de la comunidad otomí interactúan entre ellos mismos, reproduciendo dialécticamente el mismo campo de comunicación.

Este mismo campo de comunicación e interacción dentro de la localidad mantiene dos esferas fundamentales: la unidad familiar y la comunidad. En la primera, se reproduce el poblado biológica, económica y parcialmente en lo cultural; mientras, que en la segunda esfera, la reproducción sucede en el orden político y cultural de una manera más amplia. 
Así, la unidad doméstica da la pauta a obtener los ingresos materiales necesarios para la manutención de los individuos; por su medio se alcanza un trozo de tierra para sembrar, o se reparten las labores alternas ante el deterioro de la economía campesina tradicional, definiendo en la lógica familiar más que en la individual, el destino de sus miembros: trabajo externo en alguna ciudad, dedicado a prepararse escolarmente, trabajador de tiempo completo en las tareas agrícolas. La familia es el espacio íntimo donde los miembros nuevos adquieren las primeras pautas culturales de la colectividad, ahí se determina si el niño o la niña aprenden español u otomí, si usa el atuendo tradicional o viste con ropas de origen externo, o bien, si ayuda al abuelo en el cuidado de la milpa y los animales, o por el contrario, parte con otros parientes a México, u otra urbe, para estudiar y trabajar

La otra esfera corresponde a la localidad y en donde la fiesta patronal es claro ejemplo de ello como ya se ha visto. Junto a ella, ocurren otros eventos religiosos como las peregrinaciones a la Basílica de Guadalupe, en la ciudad de México; y al Santuario de Chalma; a ellas asisten en calidad de habitantes de San Mateo Capulhuac, lo cual queda escrito textualmente en las mantas que colocan en los lados de la camionetas que acompañan a los contingentes de peregrinos y en el estandarte que encabeza al grupo de sanmateinos durante su caminar hasta el templo guadalupano de La Villa, en él también se anota con todas sus letras el nombre de "San Mateo Capulhuac". Por lo tanto, el espacio comunitario resulta un punto de socialización que educa para la adscripción con pueblo a través de la participación en las mayordomías y en los cargos civiles -delegados, comisionados del agua, sociedad de padres de familia de las escuelas, etc.-, resultando así en punto de referencia de la lealtad para con su comunidad, en la medida en que deben servirla. Fuera de la localidad, las lealtades van decreciendo, el nivel municipal implica compromisos, con el ayuntamiento o la parroquia de la cabecera municipal de Villa Cuauhtémoc, se identifican con la ciudad de Toluca, con su estado y el país, pero estos otros niveles de adscripción resultan más lejanos, son lugares distantes en lo territorial y lo social, es decir, son sitios con los que sus relaciones sociales resultan poco frecuentes y menos comprometidas. Por el contrario, los tratos entre los mismos miembros de la localidad, se patentizan en eventos religiosos y civiles, como los mencionados, y su incumplimiento trae por consecuencia la condena del grupo de pertenencia, una condena cotidiana salvada sólo por la 
autoexpulsión del pueblo, lo que significa la fractura de las lealtades comunitarias y de las relaciones sociales internas de reciprocidad, tal es el caso de los migrantes permanentes.

Autoidentificarse y ser identificados por otros como miembros de un grupo étnico. La situación de la identidad puede observarse, en una primera instancia, entre los miembros de la misma localidad, esto queda patentizado por el culto a un mismo santo patrono: su propia imagen de san Mateo, adorado en su templo -recuérdese, símbolo de la matriz original-, lo que les diferencia respecto de otras imágenes del mismo santo y otros templos católicos. Es decir, la adscripción se codifica por medio de un espacio sacralizado, la iglesia del pueblo; y por una imagen peculiar, asociada con ellos mismos. No cabe posibilidad de confusión.

A este conjunto de relaciones sociales les doy el nombre de intrarrelaciones étnicas locales (Ramírez Torres, 1985) las que en el contexto étnico de San Mateo Capulhuac define la adscripción a una localidad, y no a un grupo amplio definido apenas por la lengua común. Esta interpretación de la identidad étnica circunscrita al nivel de la localidad, ha sido señalada con anterioridad para los casos tzotzil y tzeltal de los Altos de Chiapas por Andrés Medina, quien anota que para estos hablantes chiapanecos no se ha creado un sólo organismo social, político o cultural y en contraparte se encuentran dispersas sus comunidades en un basto territorio en el que las unidades sociales significativas son los pueblos, en cuya cabecera se distinguen las construcciones donde se efectúan las actividades económicas, políticas y religiosas, es decir, el mercado, el cabildo y la iglesia (Medina,1983: 7). Una experiencia documentada en el mismo sentido, aunque distante del territorio mesoamericano, lo constituye el de los hablantes de aymara, en Bolivia; ahí la identificación más profunda y el grupo de referencia más obvio para la mayoría de estos indígenas es su propio lugar de origen, por lo que un campesino más que "campesino" o "aymara", se asume como miembro de tal comunidad, o de la región en torno a tal o cual pueblo y quizás de tal o cual provincia (Albó, 1979: 481-2).

Las condiciones negativas en la producción agrícola son aminoradas con el trabajo asalariado y el comercio ejercidos en las ciudades a donde se trasladan los migrantes temporales, situación que no es motivo para distanciar las intrarrelaciones étnicas, degradar 
demográficamente a la comunidad, ni mucho menos para pronosticar su desaparición; las fiestas por motivos de matrimonio o bautizo, los funerales, y la celebración anual en honor al santo patrón, son motivo para visitar la comunidad de origen, permitiendo la continuidad de las relaciones intralocales y por ende la autoperpetuación del mismo poblado. Con las intrarrelaciones sociales como marco, los individuos comparten valores culturales comunes: sistema religioso, manejo dual de las lenguas español-otomí, conjugación de vestido tradicional con el "occidentalizado", existencia de casas de adobe contiguas a habitaciones construidas con materiales y diseños "modernos", entre otros muchos componentes.

De no compartir valores comunes sería prácticamente imposible mantener un mismo campo de comunicación. Esto es que, para relacionarse los individuos de Capulhuac entre ellos mismos, es necesario manejar el mismo código cultural, ya que de lo contrario no podría haber tal comunicación, y en consecuencia no cabría relación alguna: para que dos personas se relacionen deben hablar en los mismos términos, y dicha comunicación no se limita a la verbalizada, sino que recurre a infinidad de canales: corporales, de atuendo, en su vivienda, o durante las ceremonias religiosas.

Lo anterior aplicado al caso específico de Capulhuac, en calidad de entidad local autorreproducida biológica, social y culturalmente, nos lleva a observar qué tanto se identifica así misma y es identificada por otras comunidades como tal. La localidad es identificada tanto por sus integrantes como por sus vecinos en dicha condición, si bien este rasgo es compartido por los poblados mestizos de la región, las diferencias culturales los hacen contrastantes para con ellos, a la vez que los acercan a otros hablantes de otomí, ejemplo de esto ocurre con sus vecinos otomíes de Jilotzingo; pero, por el contrario, no sucede con otros hablantes de otomí como aquellos que habitan municipios desconocidos o de percepción lejana a los de esta región, tales son los casos de Acambay o San Bartolo Morelos del mismo Estado de México, u otros geográficamente más lejanos como los de entidades federativas de Hidalgo y Querétaro; al respecto, cabe mencionar que en una plática, mantenida por quien esto escribe con un alfarero otomí del municipio de Temoaya, el artesano afirmó que la lengua hablada por los de Acambay definitivamente no era otomí, al insistirle respondió: "pos quien sabe qué será, pero ellos no son de otomí'. Es decir, las autoidentificaciones se delimitan más por criterios locales 
que por conciencias lingüísticas ampliadas, de aquí mi conclusión de que el espacio étnico se concreta en la localidad, habiendo elementos para ampliarla a los otros poblados de la misma lengua, pero obstaculizada por el estrecho radio de relaciones intercomunitarias. De esta forma es que San Mateo Capulhuac guarda relaciones con comunidades vecinas, a las que identifica como otomíes, es conocido por sus habitantes que en Temoaya, San Pedro Arriba, Magdalena, Jilotzingo, San Cristóbal, San Pablo, San Lorenzo, San Mateo Mozoquilpan, San Felipe, Villa Cuauhtémoc, Xonacatlán y Santiago, en mayor o menor proporción, también se habla otomí. Las redes sociales tejidas entre ellas, aunadas con su cercanía espacial, permite el contacto de los habitantes de San Mateo Capulhuac con dichos lugares.

Al interior de San Mateo, las intrarrelaciones otomíes han abandonado instancias de cohesión social tradicional, como la de los oratorios y de los que actualmente ya no hay vestigios en Capulhuac; éstos cumplían funciones de cohesión social a través de las relaciones de compadrazgo que se establecían en torno al culto a las imágenes adoradas en ellos, en los términos en que ha sido registrado todavía en la segunda mitad del presente siglo, en comunidades mazahuas (Cortés Ruiz, 1972).

Hoy en día, las instancias de cohesión social rebasan los límites culturales tradicionalistas otomíes, adoptando innovaciones que cumplen funciones de adscripción étnica local, incluso en el orden lingüístico. Los nuevos miembros de la comunidad son enseñados a hablar tanto en otomí, como en español; de 32 familias conocidas, en una se enseñaba a hablar a los niños en otomí; en 28 familias se hacía en español; y en tres de ellas se les hablaba a los niños para su adquisición lingüística en forma bilingüe. Esto significa que a pesar de que, entre una parte de las nuevas generaciones, la lengua materna sea el castellano, finalmente la socialización de ellos sucede al interior de una comunidad que se autoperpetúa biológicamente, posee valores culturales comunes, está integrada por un campo de comunicación e interacción, y se autoidentifica y es identificada por otros como peculiar. Esto a pesar de que su caracterización cultural no equivale a un tradicionalismo radical, ya que una postura de este tipo provocaría su aniquilamiento social ante el deterioro económico producto del minifundismo y la degradación del entorno natural, factores que exigen un flujo migratorio y modificar las condiciones internas adecuadas a las condiciones imperantes del momento. 
En consecuencia, si bien se han perdido símbolos étnicos tradicionales de cohesión comunitaria, como el oratorio, por el contrario se adoptan innovaciones culturales que antes de desarticular sus referentes étnicos, se ofrecen en calidad de mecanismos de integración y reproducción localista otomí, innovaciones que en lugar de ser síntomas de decadencia de la etnicidad se convierten en agentes de fortalecimiento de la comunidad otomí misma.

\section{Conclusiones}

La recodificación cultural permite solucionar, a favor de la reproducción étnica local, la tensión ocurrida entre la desocialización derivada del minifundismo-emigración y la resocialización lograda por medio de innovaciones culturales agregadas a las pautas tradicionales de cohesión social. Para conseguirlo se han cambiado aspectos tradicionales otomíes, eliminando componentes -por ejemplo, el oratorio-, o bien modificando su significado y función -por ejemplo, las lenguas otomí y español-.

Las transformaciones invaden al conjunto de los habitantes de la comunidad, como en San Mateo, ya que si no fuera así, los diversos préstamos culturales adoptados principalmente por los jóvenes, serían un factor de incomunicación al tratar de relacionarse con los niños, adultos y ancianos. Sin embargo, al hacer un todo coherente que reúne la permanencia significante del cerro Ojo de Agua con el culto a san Mateo y el flujo de ingresos monetarios para gastos domésticos y rituales, se construye entonces un lenguaje nuevo, el cual no debe ser entendido como sinónimo de desarticulación de la etnicidad otomí, muy por el contrario, la gestación de esta nueva forma debe de ser comprendida a la luz de la historia indígena de la región, la cual señala que las influencias nahuas y posteriormente las hispanas, no fueron, con todo y sus militarismos, suficientes para desintegrar la reproducción comunitaria.

De la misma manera, el minifundismo, la emigración y los cambios que esto imprime no se ofrecen como datos que prueben su aniquilamiento étnico, más aún, de estos mismos cambios los otomíes toman préstamos culturales que son por ellos refuncionalizados para cumplir la misión de reproducirlos en calidad de comunidades otomíes. Los cambios en el código cultural evitan el anquilosamiento de los símbolos comunicativos tradicionalistas, el cambio los recontextúa, permitiendo revitalizar un código otomí para todos: 
ancianos, adultos niños, hombres y mujeres, campesinos y comerciantes, albañiles y pastores; cambios que pasan siempre por el filtro de la recodificación comunitaria otomí. Con este nuevo código se comunican al interior de su comunidad y con otras localidades otomíes, a la vez que interactúan con los miembros de sociedades ajenas étnicamente, actualmente necesarias para inyectar recursos que requiere la localidad en estos tiempos de deterioro económico.

Email:jlrt@coatepec.uaemex.mx

\section{Bibliografía}

Albó, Javier (1979), “¿Khitipxtansa? ¿Quiénes somos? Identidad localista, étnica y clasista en los aymaras de hoy", en América Indígena, año XXXIX, vol. XXXIX, no. 3, julio-septiembre, 1979, México: Instituto Indigenista Interamericano.

Álvarez Lobato, Ma. Elena (1991), Diagnóstico de salud de San Mateo Capulhuac, Toluca: Instituto de Salud del Estado de México.

Arizpe, Lourdes (1978), Migración, etnicismo y cambio económico. Un estudio sobre migrantes campesinos en la ciudad de México, México: El Colegio de México.

Barth, Fredrik (1976), Los grupos étnicos y sus fronteras, México: FCE.

Bartra, Armando (1982), El comportamiento económico de la producción campesina, México: Universidad Autónoma de Chapingo.

Bartra, Roger (1980), "Los campesinos: una extinción imposible en marcha permanente", en Antropología y Marxismo, no. 2, septiembre de 1979-marzo1980, México.

Carrasco Pizana, Pedro (1979), Los otomíes. Cultura e historia prehispánica de los pueblos mesoamericanos de habla otomiana, Toluca: Biblioteca Enciclopédica del Estado de México.

Cortés Ruiz, Efraín C. (1972), San Simón de la Laguna. La organización familiar y lo mágico religioso en el culto al oratorio, México: SEP Instituto Nacional Indigenista.

Chevalier, Jean y Gheerbrant, Alain (1986), Diccionario de los símbolos, Barcelona: Editorial Herder.

Douglas, Mary (1973), Pureza y peligro. Un análisis de los conceptos de contaminación y tabú, Madrid: Siglo Veintiuno Editores.

Eliade, Mircea (1979), Imágenes y símbolos, Madrid: Editorial Taurus. (1985), Lo sagrado y lo profano, Barcelona: Editorial Labor/Punto Omega.

Galinier, Jacques (1990), La mitad del mundo. Cuerpo y cosmos en los rituales otomíes, México: Universidad Nacional Autónoma de México.

Giménez, Gilberto (1978), Cultura popular y religión en el Anáhuac, México: Centro de Estudios Ecuménicos, A. C.

Godelier, Maurice (1976), Antropología y biología, Barcelona: Editorial Anagrama.

Hardesty, Donald L. (1979), Antropología ecológica, España: Ediciones Bellatierra.

IIIGEC (1993), Atlas general del Estado de México, volumen II, Toluca: Instituto de Información e Investigación Geográfica, Estadística y Catastral.

INEGI (1991), XI censo de población y vivienda, 1990. Estado de México, México: Instituto Nacional de Estadística, Geografía e Informática. 
Lagarriga, Isabel (1974), "Explicaciones causales de la autoidentificación étnica dadas por los habitantes de la región otomí del norte del Estado de México", en Beatríz Oliver Vega, Los grupos otomianos, Cuadernos de Trabajo, técnicas 2, México: Instituto Nacional de Antropología e Historia.

Levi-Strauss, Claude (1992), El pensamiento salvaje, México: FCE.

Martínez, Maximino (1987), Catálogo de nombres vulgares y científicos de plantas mexicanas, México: FCE.

Mc Clung de Tapia, Emily (1990), “Ecología, agricultura y ganadería durante la Colonia”, en Gonzalo Aguirre Beltrán y Roberto Moreno de los Arcos, Historia general de la medicina en México. Medicina novohispana, siglo XVI, tomo II, México: Universidad Nacional Autónoma de México.

Medina, Andrés (1983), "Los grupos étnicos y los sistemas tradicionales de poder en México", e: Nueva Antropología, vol. V, no. 20, enero de 1983, México.

Mendizábal, Miguel Othón de (1946), "El santuario de Chalma", en Obras Completas, tomo II, México: Talleres Gráficos de la Nación.

Quezada, Noemí (1972), Los matlazincas. Época prehispánica y época colonial hasta 1650, México: Instituto Nacional de Antropología e Historia.

Ramírez Torres, Juan Luis (1985), La formación del símbolo en el niño mazahua migrante. El caso de La Merced, tesis, México: Escuela Nacional de Antropología e Historia.

Sahagún, Fr. Bernardino (1979), Historia general de las cosas de la Nueva España, México: Porrúa.

Sahlins, Marshall (1964), "Cultura y medio ambiente: el estudio de la ecología de las culturas", en Sol Tax (comp.), Antropología: una nueva visión, Cali: Editorial Norma.

(1988), Islas de historia. La muerte del capitán Cook. Metáfora, antropología e historia, Barcelona: Gedisa Editorial.

Soustelle, Jacques (1935), Le culte des oratoireschez les Otomis et les Mazahuas de la région d'Ixtlahuaca, t. III. 1935, nos. 5-8,México: El México Antiguo. (1980), México, tierra india, México: Sep/Setentas/Diana.

(1993), La familia otomí-pame del centro de México, Toluca: Instituto Mexiquense de Cultura y Universidad Autónoma del Estado de México.

Sugiura, Yoko y Serra, Mari Carmen (1983), "Notas sobre el modo de subsistencia lacustre. La laguna de Santa Cruz Atizapán, Estado de México", en: Anales de Antropología, I Arqueología y Antropología Física, vol. 20, México: Instituto de Investigaciones Antropológicas, Universidad Nacional Autónoma de México.

Wolf, Eric R. (1978), Los campesinos, Barcelona: Editorial Labor. 